\title{
O VALOR DOS SERVIÇOS DA NATUREZA NO CÁLCULO DOS CUSTOS DE PRODUÇÃO AGRÍCOLA.
}

\author{
Frederico Silva Thé Pontes \\ Doutor em Economia Rural e Professor do Departamento de Agrotecnologia e Ciências Sociais da UFERSA \\ E-mail: frederico@ufersa.edu.br. \\ Frederico Silva Thé Pontes Filho \\ Engenheiro Agrônomo e aluno do Curso de Economia da UERN \\ E-mail: fredericopontesf@yahoo.com.br. \\ Felipe Moura Pontes \\ Aluno do Curso de Agronomia da UFERSA \\ E-mail: hamtaro_op@hotmail.com. \\ Antonia Mirian Nogueira de Moura Guerra. \\ Aluna de Graduação em Agronomia da UFERSA, Mossoró - RN \\ E-mail mirianagronoma@hotmail.com \\ Tadeu Fladiner Costa Pereira \\ Aluno de Agronomia da UFERSA - Universidade Federal Rural do Semi-Árido e membro do GVAA - Grupo \\ Verde de Agricultura Alternativa. Mossoró - RN. \\ E-mail: fladner@gmail.com
}

Resumo - O trabalho discute a importância da contribuição da natureza (através da disponibilidade de recursos não econômicos - sem preço de mercado) ao processo de produção agrícola. $\mathrm{Na}$ análise econômica da atividade agrícola, em condições experimentais, essa contribuição é considerada apenas do lado da receita, sendo negligenciada no cálculo dos custos de produção que são baseados em planilhas de custos envolvendo gastos com insumos, mão-de-obra, máquinas e equipamentos. Os custos referentes aos serviços da natureza podem ser indiretamente estimados, incorporando aos custos a contribuição dos fatores fixos da propriedade rural necessários ao aproveitamento dos benéficos da natureza. $\mathrm{O}$ artigo finaliza apresentando um exemplo de como essa contribuição pode ser minimamente dimensionada.

Palavras Chaves: Custos de produção, Economia rural e valor de serviços

\section{THE VALUE OF THE SERVICES OF THE NATURE IN THE CALCULATION OF THE COSTS OF AGRICULTURAL PRODUCTION.}

\begin{abstract}
Summary - The work argues the importance of the contribution of the nature (through the availability of not economic resources - without market price) to the process of agricultural production. In the economic analysis of the agricultural activity, in experimental conditions, this contribution is considered only of the side of the income, being neglected in the calculation of the production costs that are based on spread sheets of costs having involved expenses with imputes, man power, machines and equipment. The referring costs to the services of the nature can indirectly be esteem, incorporating the costs the contribution of necessary the fixed factors of the country property to the exploitation of the beneficial ones of the nature. The article finishes presenting an example of as this contribution can minimum was measure.
\end{abstract}

Words Keys: Costs of production, agricultural Economy and value of services 


\section{INTRODUÇÃO}

Hoje, mais que nunca, os resultados da pesquisa agronômica devem obrigatoriamente passar pelo crivo legitimador da teoria econômica, sem o qual o desempenho produtivo resultante da introdução de novas tecnologias de produção agrícola não serve de parâmetro para decisão de adotar tais inovações.

Num mundo atual no qual produtos e produtores competem numa esfera global cada vez mais abrangente e inexorável, os preços de mercado (de fatores e produtos) são os mais valiosos indicadores do rumo que deve tomar o processo produtivo. Somente uma teoria que incorpore os sinais de preço ao processo de decisão empresarial, ou seja, que ofereça ao tomador de decisão um referencial metódico/lógico, tendo por base a relação benéfico/custo no uso dos recursos econômicos, poderia mensurar com maior realismo a viabilidade do uso de novas tecnologias de produção.

Hayami e Ruttan (1971) citados por Accarini (1987), afirmam que o desenvolvimento rural depende da habilidade em se adotar alternativas tecnológicas que facilitem a substituição de fatores de produção relativamente escassos e, portanto, mais caros, por fatores relativamente abundantes $e$, consequentemente, mais baratos. De acordo com aqueles autores, são os sinais de mercado que induzem o desenvolvimento tecnológico na agricultura. Para compreender estes sinais, ou seja, para incorporá-los de forma adequada ao processo de tomada de decisão do produtor rural, é indispensável o uso de um método confiável e eficaz que explicite a relação benéfico/custo de cada decisão.

Muito pode ser dito sobre a imprescindibilidade da teoria econômica como referencial inerente ao processo de tomada de decisão sobre o que, quanto e como produzir. A despeito desse imperativo, a incorporação definitiva da análise econômica aos resultados da pesquisa agronômica feitas em campos experimentais ainda é uma meta a ser atingida. No ambiente acadêmico as experiências agronômicas são realizadas em escalas diminutas e em locais privilegiados que em nada traduzem a realidade de campo. Portanto, o grande problema da análise econômica de experimentos agrícolas não está associado somente à necessidade premente $\mathrm{e}$ irrevogável de vulgarizar a avaliação econômica dos experimentos agrícolas; a dificuldade maior reside na possibilidade de se proceder a uma avaliação econômica adequada e realista, principalmente no que se refere ao dimensionamento dos custos de produção na agricultura em virtude da contribuição de fatores naturais para os quais não existe preço de mercado.

Este trabalho discute a importância da contribuição da natureza (através da disponibilidade de recursos não econômicos - sem preço de mercado) ao processo de produção agrícola, apresentando um exemplo de como essa contribuição pode ser minimamente auferida ao simular, em escala mínima, reais condições de campo.

\section{Os Serviços da Natureza na Produção Agrícola}

Diferente do que ocorre na indústria, o tempo de produção na agricultura é maior que o tempo de trabalho. Em boa parte do tempo, o agricultor espera que a natureza cumpra seu papel no processo de desenvolvimento das plantas.

No desempenho de suas funções, a natureza lança mão dos mais variados fatores que prestam os mais variados e indispensáveis serviços, como água, minerais, vento, luz, variações térmicas, insetos polinizadores e o próprio tempo, composto de dias e noites, necessário ao 


\section{REVISTA VERDE DE AGROECOLOGIA E DESENVOLVIMENTO \\ SUSTENTÁVEL \\ GRUPO VERDE DE AGRICULTURA ALTERNATIVA (GVAA)}

cadenciado e sucessivo mecanismo de fotossíntese e respiração. A reação, no interior da célula vegetal, envolvendo o gás carbônico e a água, na presença de luz, gera matéria orgânica e, como se não fosse o bastante, fornece ao ambiente o, cada vez menos abundante, oxigênio.

Esse milagre da natureza de transformação do inorgânico em orgânico, inspirou os fisiocratas, um grupo de economistas franceses do século XVIII, a desenvolver, de modo sistêmico e lógico, a teoria do liberalismo econômico, transferindo o centro da análise do âmbito do comercio (mercantilismo da época) para a produção. Ao desenvolver o conceito de produto líquido, esse grupo de economistas sustentou que somente a terra ou a natureza é capaz de produzir algo novo. De acordo com Sandroni (1989), para os fisiocratas "só a terra multiplica, por exemplo, um grão de trigo em muitos outros grãos de trigo". A agricultura seria, assim, a única geradora de mais valor, cabendo ao outros setores da economia (indústria e comercio) a transformação ou transporte dos produtos da terra.

$\mathrm{O}$ que os fisiocratas perceberam como sendo o poder da terra em gerar, "por si só", valor adicional, representa uma verdade parcial; parcialidade que se manifesta na subestimação dos custos envolvidos na apropriação dos benefícios da natureza. Não se trata, portanto, de negar a importância dos serviços prestados à produção agrícola pelos recursos naturais, mas compreender que para fazer jus aos serviços imputados pela natureza, a empresa rural deve dispor de uma grande área de terra, de estradas, de cercas, de construções (silos, armazéns, casa de trabalhadores, garagem para máquinas e as próprias máquinas); tudo isso implico em considerável custo fixo, sem o qual as benesses da natureza não estariam prontamente disponíveis.

\section{Custos de Produção}

O capítulo sétimo de Pindyck, 2002, inicia com a seguinte pergunta: que custos considerar? Embora o autor não se refira aos custos referentes à contribuição da natureza ao processo de produção econômica, conforme discutido anteriormente, a pergunta é sugestiva e, se ultrapassado o limite dado no citado capítulo, ou seja, o da diferença entre custo econômico e custo contábil, pode-se imaginar o processo de auto-geração da natureza como uma atividade que provoca externalidades positivas sobre outros diversos processos produtivos. Para Sandroni, 1989, externalidades são "benéficos ganhos pelas unidades produtivas que se beneficiam em decorrência da expansão de uma indústria ou de um setor industrial". Quando este "setor industrial" é a natureza, como valorar estes benefícios? Os serviços prestados por esta "indústria natural" ao processo de produção agropecuário deveriam e poderiam ser computados como um custo a ser coberto pela receita da atividade?

De acordo com Reis, 2002, custo de produção é definido como "a soma de todos os recursos (insumos e serviços) utilizados no processo produtivo de uma atividade agrícola, em certo período de tempo...". Como já mencionado, na agricultura o tempo de produção é maior que o tempo de trabalho. Durante o último, o afazer humano é o de empregar e gerenciar os fatores convencionais (terra e capital); no transcorrer do período compreendido pela diferença entre aquele e este, resultado composto de tempo de produção sem trabalho humano, um incógnito benfazejo ocupa o lugar do trabalhador, mas o benfeitor não é um autêntico altruísta, ele exige algo em troca: grandes áreas em lugares especiais, requerendo, em conseqüência, grande esforço para manutenção dessas condições especiais; e quando a natureza atua isoladamente, os trabalhadores e suas ferramentas devem ser paralisados e 


\section{REVISTA VERDE DE AGROECOLOGIA E DESENVOLVIMENTO \\ SUSTENTÁVEL \\ GRUPO VERDE DE AGRICULTURA ALTERNATIVA (GVAA)}

adequadamente abrigados em um camarim especial aguardando o próximo ato da peça em cartaz: "a produção agrícola". Como numa peça teatral da qual o ator deve tirar seu sustento, o calculo dos custos não deve corresponder unicamente ao esforço do artista no palco, que o público ver e aplaude, mas também ao esforço silencioso de corpos anônimos que a rubra cortina esconde.

As planilhas usadas para no calculo dos custos de produção, relativas a experimentos agrícolas postos em prática no interior de unidades acadêmicas de experimentação, incluem insumos, equipamentos e coeficientes técnicos envolvidos no processo de trabalho humano, as chamadas despesas operacionais do sistema de produção. Muitas vezes o custo de produção referese exclusivamente a estas despesas. Em condições de campo (na propriedade rural) deve-se incluir a depreciação do ativo fixo que prestou serviço ao produto; neste caso, se os recursos fixos que contribuíram, direta e indiretamente, para realização do produto forem corretamente identificados e mensurados, o desprezo para com a contribuição da natureza no processo produtivo estaria sendo reduzido, pois é através dos ativos fixos que a natureza se manifesta no produto: o patrimônio físico da propriedade constituise o palco sobre o qual a natureza ajuda a recita a poesia da produção agrícola. Quanto mais e melhor for dimensionado o espaço necessário e suficiente à prestação dos serviços da natureza, mais justos serão os custos imputados à produção.

Por exemplo, uma cerca fixa, há tempos construída, em torno de uma pequena área de plantio geralmente não entra no calculo dos custos de produção; por outro lado, a sua falta deixa o cultivo exposto à ação de animais herbívoros no período em que a natureza age sozinha, na ausência do trabalhador humano. Se o tempo de produção fosse igual ao tempo de trabalho, como na indústria, existiria a presença humana continuamente na área de produção e, neste caso, os animais não se aproximariam do plantio. Portanto, a natureza contribui generosamente e nunca diz não, mas cobra seu preço.

A seguir, será apresentado um exemplo ilustrativo e esquemático do cálculo do custo de produção onde são avaliadas as contribuições dos ativos fixos necessários ao desempenho das funções da natureza no processo produtivo.

\section{Um Exemplo Ilustrativo}

O exemplo discutido nesta seção não pretende ser um modelo completo do método de dimensionamento integral da contribuição da natureza no processo de produção agropecuário. Essa mensuração não é metodologicamente possível; portanto, a presente simulação objetiva mostrar como o grande estoque de fatores fixos, presentes em todas as propriedades rurais (necessários ao aproveitamento dos benéficos da natureza sobre o processo de produção) podem ser minimamente incorporados ao custo de produção, evitando que a medida dos custos se resuma a gastos com insumos, sem levar em consideração o desgaste do estoque de capital fixo da empresa.

Custo hipotético de produção de feijão cultivado em uma pequena propriedade rural do estado do Rio Grande do Norte.

Colheita: 2006

Período: outubro 2005 a junho de 2006

Região: Oeste Potiguar

Área total da propriedade: 19,2 ha

Área cultivada com feijão: 4,8 ha

Quantidade produzida: 4,5 t

Valor do arrendamento da terra: RS 30,00/ha/mês

Impostos (ITR): R \$ 200,00/ano

Benfeitorias com vida útil de 20 anos

Casa sede

$\mathrm{R} \$ 30.000,00$ 
Silo

R \$ 8.000,00

$3 \mathrm{~km}$ de cerca

$\mathrm{R} \$ 10.000,00$

Total

$\mathrm{R} \$$ 48.000,00

Equipamentos com vida útil de 10 anos

Plantadeira manual

$\mathrm{R} \$ 120,00$

Arado de boi

$\mathrm{R} \$ 150,00$

Carro de boi

$\mathrm{R} \$ 750,00$

Total

$\mathrm{R} \$ 1020,00$

Mão-de-obra

Gastos totais em aração, gradagem, plantio, capinas, colheita e secagem: $\mathrm{R} \$$

$2.440,00$.

$\underline{\text { Insumos }}$

Inseticidas, adubos e sementes: $\mathrm{R} \$$

$1.160,00$.

Trabalho do proprietário

Remuneração pelo esforço físico: $\mathrm{R} \$$

$300,00 /$ mês.

\section{Cálculo do Custo de Produção}

\section{a) CFT}

Custo de oportunidade da terra: (corresponde ao custo de oportunidade)

$\mathrm{CO}=(4,8 \mathrm{ha}) *(\mathrm{R} \$ 30,00 / \mathrm{ha} / \mathrm{mês}) *(9$ meses) $=\mathrm{R} \$ 1.296,00$

$\underline{\text { Benfeitorias }}$

Calcula-se a fração do valor das benfeitorias que é utilizada anualmente com o cultivo do feijão, ou seja, o montante da depreciação/ano, calculada pela fórmula:

$$
D A=\frac{(V A-V R)}{V U}
$$

DA - valor da depreciação anual, VA Valor atual do recurso, VR - valor residual, VU - Vida útil.

(considera-se 25\% do valor das benfeitorias, pois o cultivo de feijão corresponde a $1 / 4$ das atividades desenvolvidas na fazenda):

$(\mathrm{R} \$ 48.000,00) *(0,25)=\mathrm{R} \$ 12.000,00$

Supondo vida útil das benfeitorias de 20 anos e considerando também que não há valor residual para benfeitorias (não pode ser vendida como sucata), a depreciação é calculada da seguinte maneira:

$$
\mathrm{DA}=(\mathrm{R} \$ 12.000,00) / 20 \text { anos }=\mathrm{R} \$
$$

600,00/ano.

\section{Equipamentos}

Montante da depreciação ano, supondo vida útil dos equipamentos de 10 anos (neste caso, o valor de sucata também foi considerado nulo, embora, em relação ao animal detração - boi -, o valor residual devesse ser igual ao valor de venda do animal, quando este, devido à velhice, não mais servisse ao trabalho de tracionar carros ou implementos agrícolas).

$$
\mathrm{DA}=(\mathrm{R} \$ 1020,00) / 10 \text { anos }=\mathrm{R} \$
$$

102,00/ano.

\section{Tributação}

Imposto Territorial Rural - ITR de R\$ 200,00/ano para toda a propriedade (no caso do feijão que ocupa aproximadamente $25 \%$ da área da propriedade, o valor total do imposto sobre a propriedade da terra deve ser dividido por 4$)$.

$$
\mathrm{T}=(\mathrm{R} \$ 200,00) /(4)=\mathrm{R} \$ \mathbf{5 0 , 0 0 / a n o} \text {. }
$$

Os dados de custo são apresentados no quadro a seguir.

\begin{tabular}{lllllll}
\hline Especificações & Valor & Vida & Deprec. & Custo de & Custo & $\%$ do \\
\hline
\end{tabular}




\begin{tabular}{lcccccc}
\hline & $\begin{array}{c}\text { Atual } \\
(\mathrm{R} \$)\end{array}$ & $\begin{array}{c}\text { Útil } \\
(\mathrm{ano})\end{array}$ & $\begin{array}{c}\text { Anual } \\
(\mathrm{R} \$)\end{array}$ & $\begin{array}{c}\text { Oport. } \\
\left(\mathrm{R} \$-12 \%^{2}\right)\end{array}$ & $\begin{array}{c}\text { Fixo } \\
(\mathrm{R} \$)\end{array}$ & $\begin{array}{c}\text { Custo } \\
\text { Fixo }\end{array}$ \\
\hline Terra & - & - & - & $1.296,00$ & $1.296,00$ & 60,60 \\
Benfeitorias & $12.000,00$ & 20 & 600,00 & 72,00 & 672,00 & 31,40 \\
Equipamentos & $1.020,00$ & 10 & 102,00 & 12,00 & 114,00 & 5,30 \\
ITR & 50,00 & 1 & - & 6,00 & 56,00 & 2,70 \\
\hline Custo fixo total & & & & & $\mathbf{2 . 1 3 8 , 0 0}$ & 100,00 \\
\hline
\end{tabular}

Parcial.

2 Segundo Kuhner e Bauer, 1996, taxa de juros ou taxa de atratividade a ser adotada no uso de técnicas destinadas a escolha entre várias alternativas de investimento, consiste na taxa mínima de retorno que o investidor pretende conseguir como rendimento ao realizar algum investimento. De acordo com Leite, 1998, a taxa de juros a ser escolhida para o cálculo do custo alternativo, deve ser igual à taxa de retorno da melhor aplicação alternativa; por ser impossível a determinação deste valor, optou-se pela taxa Selic que é considerada a taxa básica de juros da economia e refletir a lucratividade média das atividades produtivas da economia. De acordo com a Recita Federal, 2007, a taxa de juros relativa ao mês de julho de 2007, aplicável na cobrança, restituição ou compensação dos tributos e contribuições federais, a partir do mês de agosto de 2007, é de $0,97 \%$ 'ou seja, aproximadamente $12 \%$.

\section{b) CVT}

\begin{tabular}{lcc}
\hline Natureza dos Custos & Dispêndio Anual (R\$) & Part. \% \\
\hline Mão-de-obra & $2.440,00$ & 28,70 \\
Insumos $^{1}$ & $1.160,00$ & 13,60 \\
Trabalho Próprio $^{2}$ & $2.700,00$ & 31,70 \\
Benfeitorias $^{2}$ & $1.200,00$ & 14,10 \\
Equipamentos $^{3}$ & 102,00 & 1,10 \\
SUBTOTAL $^{\text {Custo de oportunidade }}{ }^{4}$ & $7.602,00$ & 86,20 \\
\hline Custo Variável Total CVT (CVT) $^{\text {Tul }}$ & 912,00 & 10,00 \\
\hline
\end{tabular}

${ }^{1}$ Fertilizantes, defensivos e sementes.

$210 \%$ para manutenção e conservação.

$310 \%$ para manutenção e conservação.

${ }^{4}$ Juros de $12 \%$.

c) $\mathbf{C T}=\mathrm{CFT}+\mathrm{CVT}$

$$
\mathrm{CT}=\mathrm{R} \$ 2.138,00+\mathrm{R} \$ 8.514,00=\mathrm{R} \$ \mathbf{1 0 . 6 5 2 , 0 0}
$$

d) Custo Operacional Total de Produção (CopT) - é igual ao CT menos os custos de oportunidade do capital (Fixo) estável e do capital circulante (Variável) (CopT $=\mathrm{CT}-$ $(\mathrm{COCF}+\mathrm{COCV}))$.

$$
\mathrm{COP}=(\mathrm{R} \$ 10.652,00)-[(\mathrm{R} \$ 1.386,00)+(\mathrm{R} \$ 912,00)]=\mathrm{R} \$ \mathbf{8 . 3 5 4 , 0 0}
$$

e) Custo Operacional Fixo Total (CopFT) - é igual ao CFT menos os custos de oportunidade referentes ao capital fixo $(\mathrm{CopFT}=\mathrm{CFT}-\mathrm{COCF})$

$$
\mathrm{CopFT}=(\mathrm{R} \$ 2.138,00)-(\mathrm{R} \$ 1.386,00)=\mathrm{R} \$ \mathbf{7 5 2 , 0 0}
$$


f) Custo Operacional Variável Total (CopVT) - é igual ao CVT menos os custos de oportunidade referentes ao capital variável $(\mathrm{CopVT}=\mathrm{CVT}-\mathrm{COCV})$

$\mathrm{CopVT}=(\mathrm{R} \$ 8.514,00)-(\mathrm{R} \$ 912,00)=\mathrm{R} \$ \mathbf{7 . 6 0 2 , 0 0}$

e) Custos Médios

Custo Fixo Médio $(\mathrm{CFMe})=(\mathrm{CFT}) /(\mathrm{Q})=(\mathrm{R} \$ 2.138,00) /(4.500 \mathrm{~kg})=\mathrm{R} \$ \mathbf{0 , 4 7} / \mathbf{k g}$. Custo Variável Médio $(\mathrm{CVMe})=(\mathrm{CVT}) /(\mathrm{Q})=(\mathrm{R} \$ 8.514,00) /(4.500 \mathrm{~kg})=\mathrm{R} \$ \mathbf{1 , 8 9} / \mathbf{k g}$. Custo Total Médio $(\mathrm{CTMe})=(\mathrm{CT}) /(\mathrm{Q})=(\mathrm{R} \$ 10.652) /(\mathrm{Q})=\mathrm{R} \$ \mathbf{2 , 3 6} / \mathbf{k g}$. Custo Operacional Total $=(\mathrm{CopT}) /(\mathrm{Q})=(\mathrm{R} \$ 8.354,00) /(4.500 \mathrm{~kg})=\mathrm{R} \$ \mathbf{1 , 8 6} / \mathbf{k g}$ Custo Operc. Fixo Médio $=(\mathrm{CopFM}) /(\mathrm{Q})=(\mathrm{R} \$ 752,00) /(4.500 \mathrm{~kg})=\mathrm{R} \$ \mathbf{0 , 1 7}$ Custo Operc. Variável Médio $=(\mathrm{CopVM}) /(\mathrm{Q})=(\mathrm{R} \$ 7.602,00) /(4.500 \mathrm{~kg})=\mathrm{R} \$ \mathbf{1 , 6 9}$

Análise Gráfica (considerando preço do kg de feijão, pago ao produtor, igual R \$2,50).

Custo e Receita

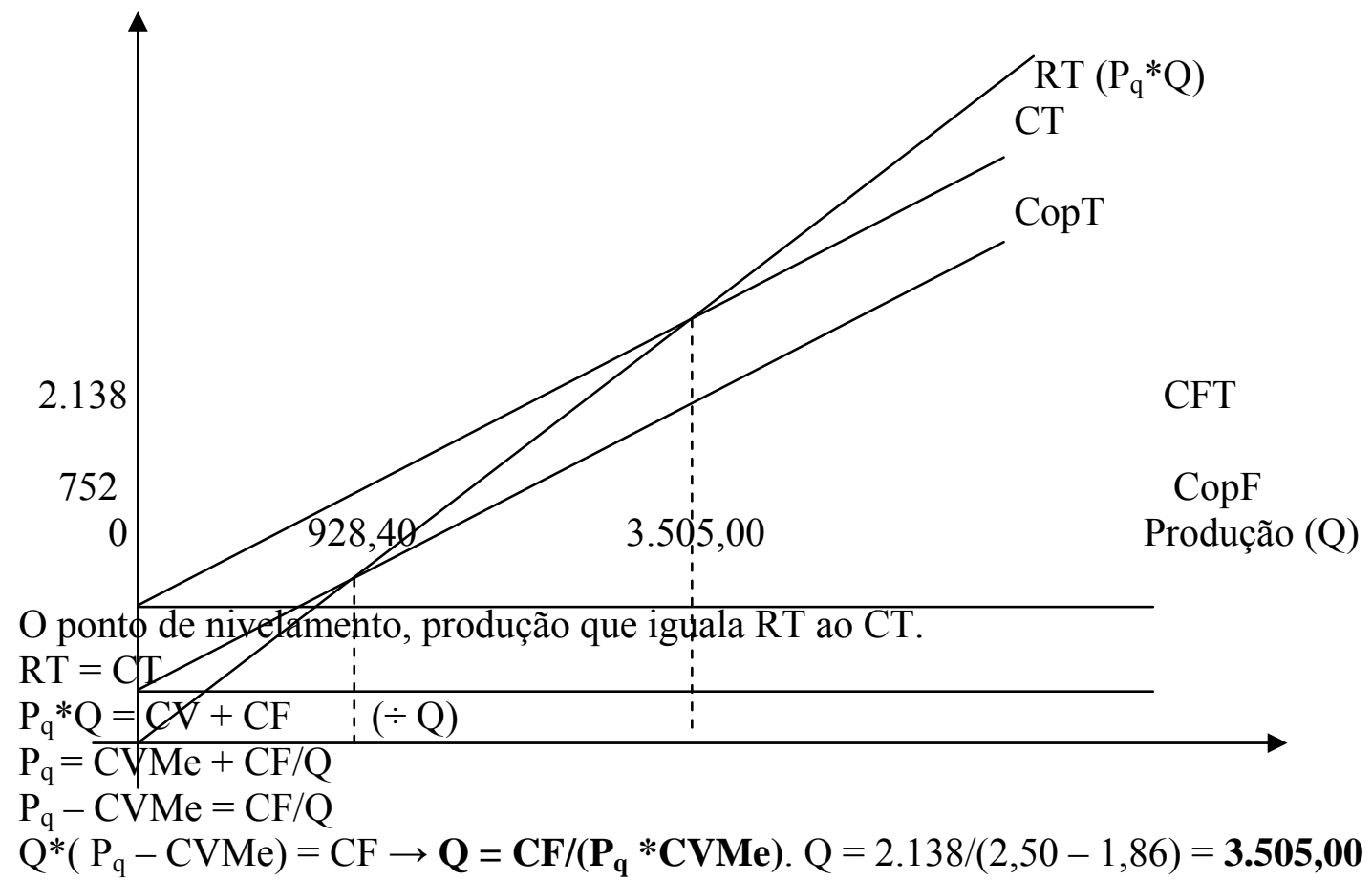

O ponto de equilíbrio $(3,5 \mathrm{t})$ foi menor que a produção na área analisada $(4,5 \mathrm{t})$, isto é, ao preço de $\mathrm{R} \$ 2,50$ as receitas seriam maiores que os custos e o produtor estaria obtendo lucro. No exemplo, o preço mínimo que o produtor poderia receber por seu produto para cobrir todos os custos (chamado preço de equilíbrio) seria de $R \$ 2,37$ (a divisão entre o custo total de $\mathrm{R} \$ 10.652,00$ e o produto total de $4.500 \mathrm{~kg}$ ). Considerando que os custos, embora hipotéticos, estão subestimados em relação ao valor real dos fatores, o preço de 2,37 reais pelo $\mathrm{kg}$ do 
produto, em termo de valor pago em nível de produtor, é alto, ou seja, é um valor que não condiz com os valores pagos ao produtor na realidade econômica dos mercados agrícolas; e se fossem considerados a totalidade dos ativos fixos que prestam serviços no processo de produção do feijão, o preço de equilíbrio seria ainda maior, indicando que a natureza presta bons e significantes serviços, mas nunca de forma totalmente gratuita.

\section{Conclusões}

Os serviços prestados pela natureza ao processo de produção agrícola, aumentando seu valor sem explícita participação do trabalho humano, constituem uma particularidade da atividade agrícola. Porém, tal contribuição pode ser minimamente avaliada incorporando aos custos de produção a contribuição dos ativos fixos da propriedade (de forma mais completa possível), sem os quais o aproveitamento das benesses da natureza seria impossível.

Nos centros de pesquisas acadêmicos onde são realizados experimentos agronômicos, a avaliação econômica das técnicas ou cultivares testados do ponto de vista do aumento da produtividade, são realizados levando-se em consideração as condições e recursos especiais dos locais onde são realizadas as experiências, ou seja, um ambiente que não reproduz as reais condições de campo; esse fato reduz a possibilidade de se estabelecer uma estrutura de custo de produção compatível com a realidade da produção na propriedade agrícola.

\section{Referências Bibliográficas}

SANDRONI, P. Dicionário de Economia. 5. ed. São Paulo: Best Seller, 1989.
ACCARINI, J. H. Economia Rural e Desenvolvimento: reflexões sobre o caso brasileiro. Petrópolis: Vozes, 1987.

LEITE, C. A. M. Planejamento da Empresa Rural. Brasília: 1998. 66p. (Curso de Especialização por Tutoria à Distância, v. 4).

KUHNER e BAUER, Matemática Financeira aplicada à Análise de Investimento. 2 ed. São Paulo: Atlas, 1996. $517 \mathrm{p}$.

REIS, R. P. Fundamentos de economia aplicada. Lavras: UFLA/FAEPE, 2002. 95p. (Texto Acadêmico) 